\title{
Radiotoxicity to Tumor Cells Enhanced By Triphala- Cellular and Animal Studies
}

\author{
Das ST and Mishra KP* \\ Foundation for Education and Research, India
}

Submission: April 22, 2018; Published: June 06, 2018

"Correspondence Address: Mishra KP, Foundation for Education and Research, Ex Radiation Biology and Health Sciences Division, Bhabha Atomic Research Centre, 504, Neelyog Residency CHS Ltd, K-1, Pant Nagar, Ghatkopar (East), Mumbai 400075, India, Tel: +91-8369845472; Fax:+91-22-25018114; Email: mishra_kaushala@rediffmail.com; mishradrkp@gmail.com

\begin{abstract}
Research results from our laboratory have shown that Triphala (TPL) induced cytotoxicity in cancer cells in vitro as well as in vivo involving the mechanism of reactive oxygen species (ROS) induced apoptosis. We have pursued this study to examine the ability of TPL to enhance radiation induced cytotoxicity in MCF-7 cells in vitro and transplantable thymic lymphoma, barcl-95 and fibrosarcoma in mice in vivo. It was found that MCF-7 cells subjected to $\gamma$-radiation (3 Gy) prior to treatment with TPL showed a significant increase in loss of viability compared with the drug treatment alone. The increased radiotoxicity of tumor cells by Triphala was found to be concentration dependant. It was further found that combined treatment of cells with $\gamma$-radiation (3 Gy) and TPL $(0.5 \mathrm{mg} / \mathrm{ml})$ induced a higher percentage of apoptosis, in MCF-7 cells than either with radiation or TPL alone. MCF-7 cells treated with TPL and $\gamma$-radiation showed a substantial increase in intracellular reactive oxygen species (ROS) and decrease in mitochondrial membrane potential. Experiments on TPL effect on tumour growth showed that TPL fed to mice (1mg/ mice/day for 14 days) for 7 days prior and 7 days after irradiation transplanted with barcl resulted in the reduction of tumor volume by $47 \%$ as compared to that of radiation treated (27\%) and TPL treated (33\%). The data showed that TPL exerted radiosensitizing effect on tumor cells in vitro as well as in vivo which may be applicable in improving cancer radio therapy.
\end{abstract}

Keywords: TPL; MCF 7; Barcl-95; Cellular cyto-toxicity; ROS; Oxidative stress

Abbreviations: TPL: Triphala; ROS: Reactive Oxygen Species; DMEM: Dulbecco's Modified Eagle's Medium; FBS: Fetal Bovine Serum; PBS: Phosphate-Buffered Saline; MTT: 3,-[4,5-dimethylthiazol-2-yl]-2,5-diphenyltetrazolium bromide; SDS: Sodium dodecyl sulphate; DCH-FDA: 2,7-dichlorodihydro Fluorescein Diacetate

\section{Introduction}

Radiation therapy is one of the most effective modalities for treatment of many tumors [1]. However, its therapeutic efficacy is often hindered by acquirement of a radioresistant phenotype by cancer cells [2]. It is frequently noticed that radioresistant cancer cells are resistant to apoptosis, often acquired as a consequence of over expression of anti-apoptotic genes [3] or through other mechanisms such as tumor hypoxia [4,5]. In the past, several drugs have been tested for their effectiveness as radiosensitizers, for e.g. hypoxic cell sensitizers such as metronidazole, misonidazole, and etanidazole etc. Clinical experience, however, with these agents have been mixed [6]. Thymidine analogues and several chemotherapeutic agents such as cisplatin, paclitaxel, doxorubicin etc. have also been studied as radiosensitizers $[7,8]$. However, most of the radiosensitizers investigated till date is found to be toxic and induce unacceptable side effects, because of which their usefulness in clinics has been limited.
In the recent past, considerable efforts have been directed to find effective anticancer substances with minimal side-effects, unlike conventional chemotherapy, which has led to the discovery of several phytochemicals and natural or herbal products with potent antineoplastic properties. Most of these agents are also found to kill cancer cells synergistically with conventional chemotherapeutic drugs and ionizing radiation [9-14]. Earlier reports from our lab has shown that Triphala (TPL), a mixture of fruits extracts of three plants in equal proportion induced cytotoxicity in several human and mouse breast cancer cell lines through reactive oxygen species (ROS) induced apoptosis. Since $\gamma$-radiation is also known to induce apoptosis in cells by a similar mechanism; we have investigated the ability of TPL to enhance radiation induced cytotoxicity in MCF 7 cells in vitro and in transplantable thymic lymphoma, barcl-95 and fibrosarcoma in mice in vivo in the present study. 


\section{Materials and Methods}

\section{Cell culture and harvesting}

Dulbecco's Modified Eagle's Medium (DMEM) was purchased from Gibco Co., USA and fetal bovine serum (FBS) was obtained from Biomedia, France. MCF 7 cells were purchased from National Centre for Cell Science, Pune, India and they were cultured in DMEM supplemented with FCS (10 \%) and antibiotics

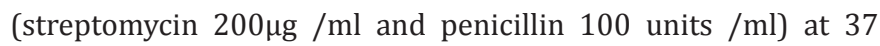
${ }^{\circ} \mathrm{C}$ in $5 \% \mathrm{CO}_{2}$ environment. Cells were harvested from $80-90 \%$ confluent culture by trypsinization and used for experiments.

\section{Preparation of TPL extract for treatment}

TPL extract in the form of powder was obtained from Ajanta Pharmaceuticals, Mumbai. Required quantity of extract powder was freshly dissolved in double distilled water and filtered through $0.22 \mu \mathrm{m}$ filter (Millipore) and used for the experiments. The TPL extract used in this study was found to contain approximately $50 \%$ gallic acid as inferred from High Performance Thin Layer Chromatographic (HPTLC) results.

\section{Determination of cytotoxicity}

One set of MCF 7 cells suspended in DMEM supplemented with FBS (10\%) were treated with $\gamma$-radiation (3 Gy) and subsequently incubated with increasing concentrations of TPL $(0.025-0.25 \mathrm{mg} /$ $\mathrm{ml})$ at $37{ }^{\circ} \mathrm{C}\left(+5 \% \mathrm{CO}_{2}\right)$ for $4-5 \mathrm{~h}$, while another set of cells were not irradiated and they were treated with TPL alone in similar conditions. Viability of cells was determined by trypan blue dye exclusion method (final concentration of dye: tenth volume of $0.4 \%$ dye in PBS).

\section{Clonogenic assay}

One set of MCF 7 cells ( $3 \times 10^{5}$ cells $/ \mathrm{ml}$ ) were allowed to settle in $30 \mathrm{~mm}$ culture dishes containing DMEM supplemented with FBS (10\%), and were incubated with increasing concentrations of TPL $(0.025-0.25 \mathrm{mg} / \mathrm{ml})$ at $37{ }^{\circ} \mathrm{C}\left(+5 \% \mathrm{CO}_{2}\right)$ for $24 \mathrm{~h}$. Two other sets of cells were treated with 3 Gy $\gamma$-irradiation either before or after treatment with increasing concentrations of TPL in culture conditions. After the desired incubation time, cells were collected after trypsinization, and washed twice with DMEM. A defined number of cells were then seeded into $100 \mathrm{~mm}$ dishes containing DMEM and FBS (10\%) and allowed to grow in culture conditions till visible colonies of more than 50 cells/colony were observed. The cells were then stained with $0.1 \%$ methylene blue dye in $80 \%$ ethyl alcohol and colonies were counted. Plating Efficiency (P.E) was calculated as number of colonies/ number of cells plated. Survival was calculated as P.E of treated /P.E of control.

\section{Determination of apoptosis}

Apoptosis induction in control as well as in cells treated by TPL was determined by using Annexin V-FITC and Propidium Iodide (PI) double staining kit (Boehringer Mannheim $\mathrm{GmbH}$, Germany) following the protocol provided along with the kit and using a fluorescence microscope (Optiphot 2, Nikon, Japan) as previously described Pandey et al. [15]. To study the concentration and time dependant effect of TPL on MCF 7 cells $\left(3 \times 10^{5}\right.$ cells/ $\mathrm{ml}$ ) were incubated with various concentrations of TPL in DMEM supplemented with FBS $(10 \%)$ at $37^{\circ} \mathrm{C}\left(+5 \% \mathrm{CO}_{2}\right)$ for 5 h. Cells were then washed with fresh medium, stained with AnnexinV-FITC and Propidium Iodide and assayed for apoptosis. From the labeled cell suspension green and red cells were counted out of 400 randomly selected cells/ sample using fluorescence microscope (Optiphot 2, Nikon, Japan). The cells showing only green fluorescence were considered apoptotic while cells showing either red or both green and red fluorescence were scored as necrotic.

To observe DNA fragmentation induced by the extract, MCF 7 cells were either treated with $0.25 \mathrm{mg} / \mathrm{ml}$ TPL for $24 \mathrm{~h}$ or $\gamma$-irradiated with 3 Gy and TPL treated and were subjected to Single Cell Gel Electrophoresis (SCGE). The images of cellular DNA were captured with a CCD camera attached to a fluorescence microscope (Zeiss) using $100 \mathrm{X}$ objective.

\section{Estimation of intracellular ROS}

The generation of intracellular ROS was measured using DCHFDA (2,7-dichlorodihydrofluorescein diacetate) as the fluorescence probe as described previously [15]. Briefly, MCF 7 cells $\left(3 \times 10^{5} / \mathrm{ml}\right)$ were incubated with various concentrations of TPL either alone or in combination with $\gamma$-irradiation in phosphate buffered saline (PBS) for $30 \mathrm{~min}$ at $37{ }^{\circ} \mathrm{C}$ followed by labeling with the fluorescence probe. Aliquots $(200 \mu \mathrm{l})$ obtained after different treatments were diluted to $3 \mathrm{ml}$ with PBS followed by measurement of fluorescence intensity $\left(\lambda_{\mathrm{ex}}=490 \mathrm{~nm}\right.$ and $\lambda_{\mathrm{ex}}$ $=520 \mathrm{~nm}$ ) in quartz cuvette using Fluorescence Spectrometer (LS50B, Perkin Elmer, USA).

\section{Assessment of Mitochondrial Membrane Potential $(\Delta \psi$ m)}

Mitochondrial membrane potential was monitored using 3,3-dihexyloxacarbocyanine iodide (DiOC6). MCF $7\left(3 \times 10^{5}\right)$ cells were treated with TPL $(0,0.05$ and $0.1 \mathrm{mg} / \mathrm{ml}$ of PBS $)$ for $30 \mathrm{~min}$ at $37^{\circ} \mathrm{C}$, either alone or in combination with $3 \mathrm{~Gy} \gamma$-irradiation (either pre/ post TPL treated), after which they were labeled with 40nM DiOC6 (3) and incubated for another 30 minutes and subsequently observed under a fluorescent microscope and photographed with a CCD camera (Zeiss). Changes in mitochondrial membrane potential were measured.

\section{Transplantation of tumor and measurement of treatment response}

The efficacy of TPL and $\gamma$-radiation treatment in reducing tumor cell growth in vivo was monitored in mouse transplanted with thymic lymphoma (barcl-95) and mouse fibrosarcoma cells. Female Swiss mice (6-8 weeks old) were divided into four groups ( 5 animals/group) followed by intramuscular transplantation of tumor cells $\left(2 \times 10^{5}\right.$ cells/mice suspended in sterile saline) in the hind leg of mice. A small tumor appeared in the form of a spherical swelling within a week. One group of mice were subjected to direct 
oral feeding of TPL extract at a dosage of $40 \mathrm{mg} / \mathrm{kg} /$ day for 14 days from the day of transplantation. Animals of the control group were given an equal volume of distilled water. Tumor size was measured after its appearance on the $7^{\text {th }}$ day after transplantation with the help of digital vernier calipers (Mitutoyo, Japan). The tumor dimension was measured at two diagonal directions and tumor volume was calculated in $\mathrm{mm}^{2}$ by formula $\mathrm{ab}^{2}(\pi / 6)$, where ' $a$ ' is the largest diameter and ' $b$ ' is the diameter perpendicular to 'a'.

\section{Statistical analysis}

The statistical analysis was performed using one-way ANOVA test using origin (version: 6.1) software.

\section{Results and Discussion}

Phytochemicals such as resveratrol found in grapes, peanuts and some berries, curcumin from turmeric, genistein from soy and Ginkgo biloba extract have been shown to enhance the radiation-induced death of cancer cells in vitro as well as in vivo [9-14,16-18]. It is also known that these natural products, which possess anticancer properties, have antioxidant properties and can, therefore, neutralize the harmful effects of reactive oxygen species on normal cells [19]. Since TPL has been shown to possess potent anticancer effects, it was of interest to find if the drug showed potentiation of radiation effects on tumor cells $[20,21]$. In the present study, we have investigated the potentiation of radiation induced toxicity by TPL in human breast cancer cells MCF 7 in vitro and on transplanted mouse tumors, barcl-95 and fibrosarcoma in vivo.

\section{TPL and $\gamma$-radiation induced cytotoxicity in MCF 7 cells}

The effects of $\gamma$-irradiation and TPL on human breast cancer cells (MCF 7) in vitro were studied using trypan blue dye exclusion method (Figure 1). Treatment of MCF 7 cells with increasing concentrations of TPL alone resulted in a progressive decrease in their viability. However, viability of MCF 7 cells treated with 3 Gy $\gamma$-irradiation and subsequent treatment with TPL showed further decrease in viability as compared to those treated with TPL or radiation alone.

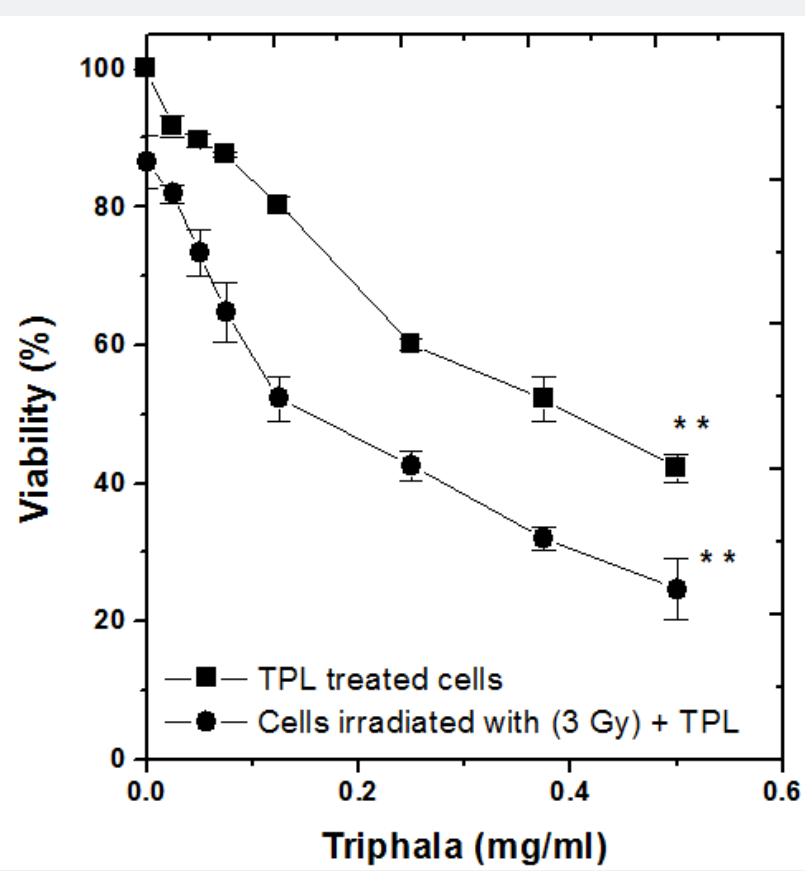

Figure 1: Effect of TPL and $\gamma$ - radiation on proliferation of human breast cancer cells. MCF-7 $\left(3 \times 10^{5}\right.$ cells $\left./ \mathrm{ml}\right)$ suspended in DMEM supplemented with FBS $(10 \%)$, either $\gamma$-irradiated/ non-irradiated were incubated with increasing concentrations of TPL at $37{ }^{\circ} \mathrm{C}(+5 \%$ $\mathrm{CO}_{2}$ ) for 4-5h. Cells were then washed with fresh medium, collected and viability of cells determined by trypan blue dye exclusion method. ${ }^{* *} p<(0.001)$.

Typically, viability of MCF 7 cells decreased by an additional 22 $\%$ for radiation and TPL combined treatment as compared to TPL treatment alone, at a TPL concentration of $75 \mu \mathrm{g} / \mathrm{ml}(\mathrm{p}<0.001)$. Cytotoxicity induced by TPL was found to be dependant on drug concentration. It was thus seen that radiation and TPL combined treatment induced almost 1.5 times greater cytotoxicity in MCF 7 cells than TPL treatment alone. In order to further confirm these results, clonogenic assay was performed.

\section{Effect of TPL and $\boldsymbol{\gamma}$-irradiation on clonogenecity of MCF 7 cells}

The 'colony formation assay' or 'clonogenic assay' is a classical test to evaluate cell growth after treatment. The assay is regularly used in oncological research where it is used to test the proliferating power of cancer cell lines after radiation and/ or treatment with anticancer agents. It was considered of interest to study TPL mediated sensitization of MCF 7 cells, when drug 
was added pre- or post-irradiation. Hence, MCF 7 cells were treated with increasing concentrations of either TPL alone or in combination with g-radiation (3 Gy, pre/post-drug treated) and incubated for $24 \mathrm{~h}$ in culture conditions (Figure 2). It was found that TPL by itself induced a progressive decrease in clonogenic ability of MCF 7 cells with increasing concentration of the drug. As compared to this, when MCF 7 cells were pre-treated with 3 Gy $\gamma$-radiation and then treated with TPL, clonogenic ability was found further decreased by an additional 22\% (Figure 2).

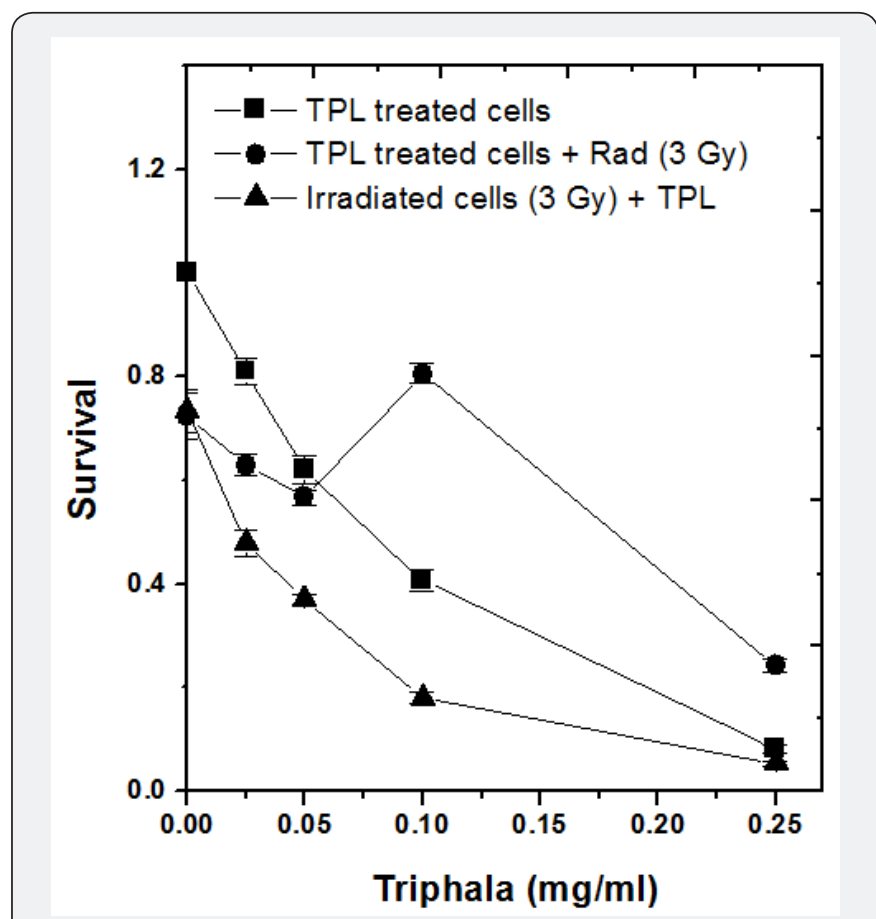

Figure 2: Effect of TPL and radiation on clonogenic ability of cells. MCF-7 cells were treated with increasing concentrations of either TPL alone or in combination with y-radiation (3 Gy, pre/ post-drug treated) and incubated for $24 \mathrm{~h}$ in culture conditions. Known no: of cells were then washed and seeded into $100 \mathrm{~mm}$ dishes containing DMEM and FBS (10\%) and allowed to grow till visible colonies were observed.

Typically, TPL treatment at a concentration of $0.1 \mathrm{mg} / \mathrm{ml}$ induced a decrease in clonogenic ability of MCF 7 cells by $60 \%$ as compared to the control, while those treated with $\gamma$-radiation initially and then treated with TPL had decreased clonogenic ability by $82 \%$, which was significant by $\mathrm{p}<0.001$. However, at this concentration of TPL $(0.1 \mathrm{mg} / \mathrm{ml})$, MCF 7 cells which were pretreated with TPL before $\gamma$-irradiation, had increased clonogenic ability as compared to that of TPL treatment alone, indicating that TPL was incapable of increasing radiation-induced toxicity of MCF 7 cells when present during irradiation. Thus it was seen that TPL enhanced $\gamma$-radiation induced toxicity in MCF 7 cells only after post-irradiation TPL treatment.

\section{TPL and $\boldsymbol{\gamma}$-radiation induced apoptosis in MCF 7 cells}

Apoptosis is commonly observed after exposure of tumor cells to radiation and/or chemotherapeutic drugs [22]. Our earlier studies have shown that $\gamma$-radiation as well as TPL induced apoptosis in MCF 7 cells [20,21]. Therefore, it was considered important to study the combined treatment of MCF 7 cells with TPL and radiation on apoptosis in these cells. The $\gamma$-radiation and TPL induced apoptosis in MCF 7 cells was determined by the loss of lipid asymmetry in apoptotic cells by measuring phosphatidylserine (PS) externalization by annexin- V staining and by monitoring the pattern of DNA fragmentation by SCGE.

It was found that TPL alone induced a concentration dependant apoptosis in MCF 7 cells as can be seen in Figure 3. However, when cells were pre-treated with 3 Gy $\gamma$-irradiation and subsequently treated with TPL, the amount of apoptosis induced increased by $9-12 \%$ with increasing concentration of the drug. This indicated that TPL enhanced radiation induced cyto-toxicity in MCF 7 cells significantly. At the highest concentration of the drug $(0.5 \mathrm{mg} / \mathrm{ml})$, apoptosis induced by TPL alone was $45 \%$, while the combination treatment of $\gamma$-radiation and TPL yielded 57\%, a significantly higher amount of apoptosis ( $p<0.001)$. In order to confirm that apoptosis was the mode of cell death induced by TPL and $\gamma$-irradiation, MCF 7 cells treated with $0.25 \mathrm{mg} / \mathrm{ml}$ TPL alone for $24 \mathrm{~h}$, either or in combination with $\gamma$-irradiation were subjected to Single Cell Gel Electrophoresis (SCGE). It was found that, the pattern of DNA fragmentation was characteristic of apoptosis with small head, constricted neck and a ballooning tail (Figure 4), which further confirmed that apoptosis was induced by TPL alone as well as in combination with $\gamma$-irradiation of MCF 7 cells.

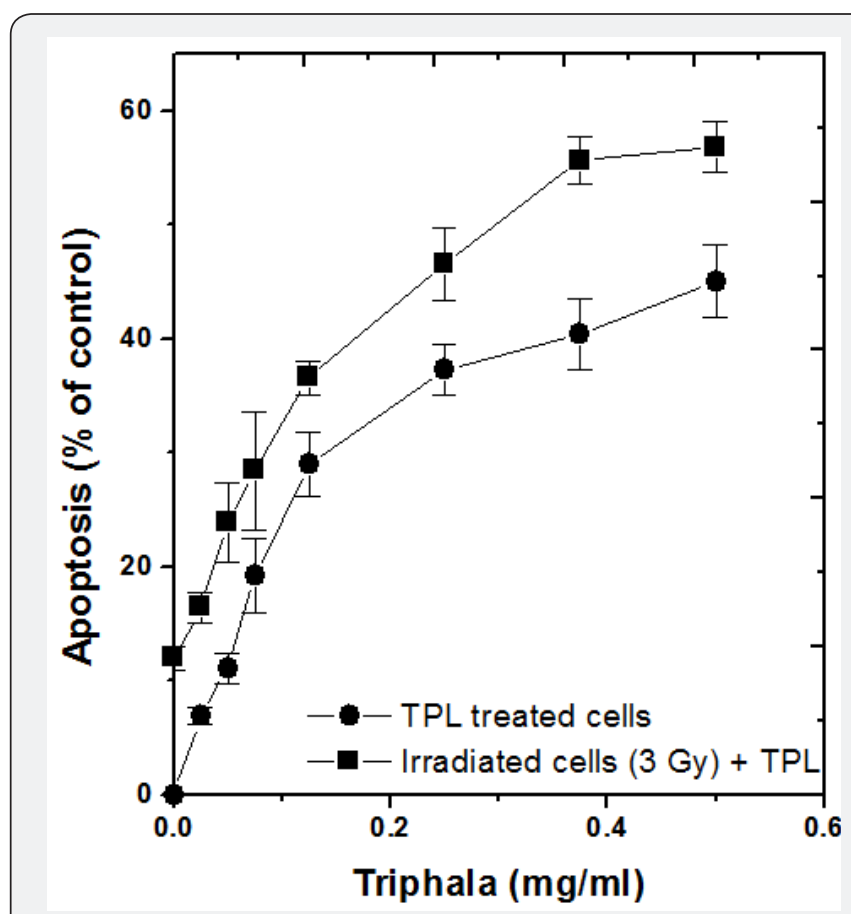

Figure 3: Detection of TPL and Radiation induced apoptosis. MCF-7 cells $(3 \times 105 / \mathrm{ml})$ were $\mathrm{y}$-irradiated ( $3 \mathrm{~Gy})$ and incubated with increasing concentrations of TPL under culture conditions for $5 \mathrm{~h}$, following which cells were washed with fresh medium and collected. Percentage apoptosis was determined by AnnexinVFITC and Propidium lodide (PI) double staining. 


\section{Cancer Therapy \& Oncology International Journal}
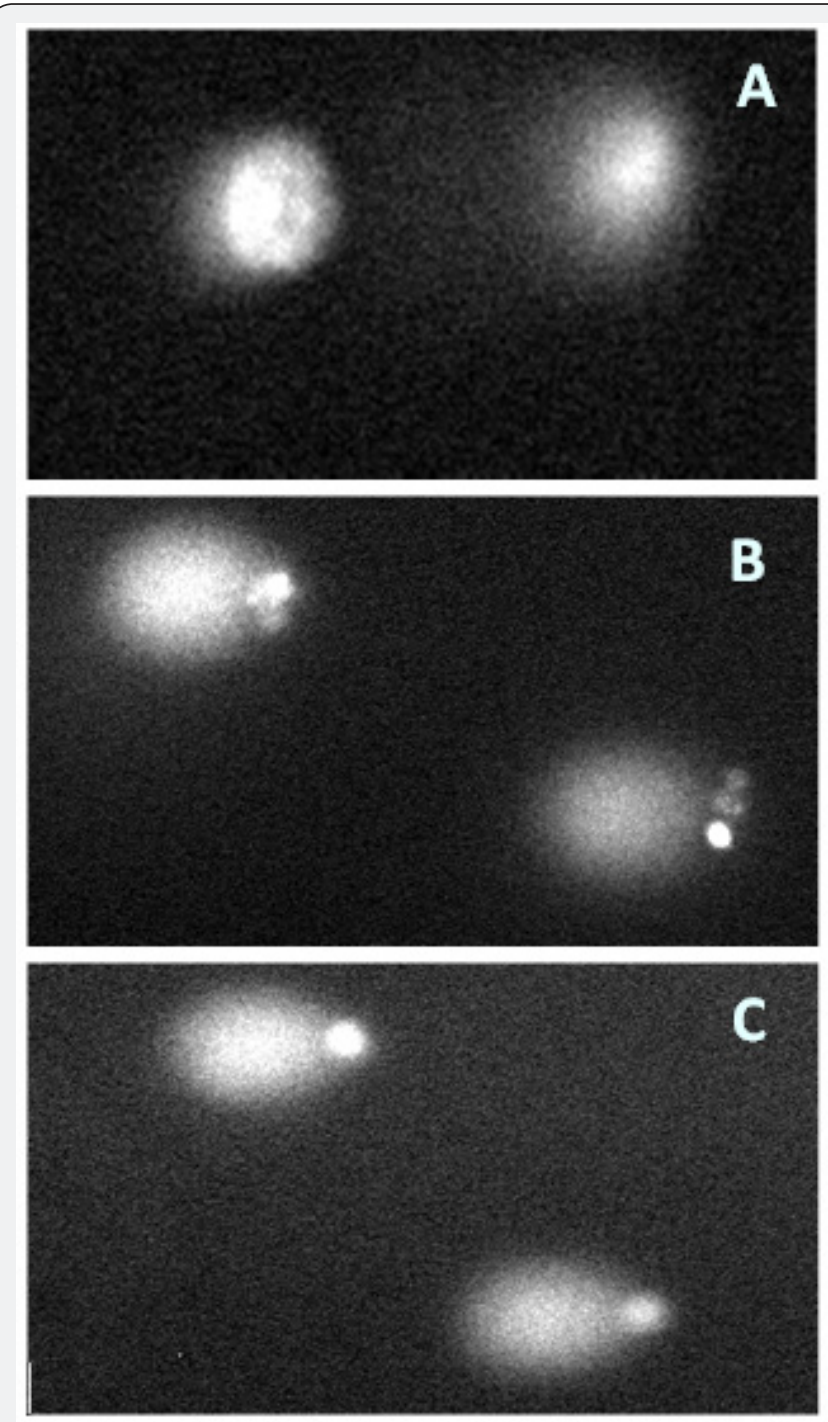

Figure 4: Characteristic DNA damage induced by TPL and radiation in MCF-7 as seen after SCGE assay. A: Control B: TPL treated $(0.25 \mathrm{mg} / \mathrm{ml}$ for 24 hours) and C: 3 Gy $\gamma$-irradiated and $0.25 \mathrm{mg} / \mathrm{ml} \mathrm{TPL}$ treated). The images of the cell DNA were captured with a CCD camera attached to a fluorescence microscope (Zeiss) using a $100 \mathrm{X}$ objective.

\section{TPL and $\gamma$-irradiation induced intracellular ROS in MCF 7 cells}

Radiation is known to induce damage to cells invariably by generation of ROS. TPL too was found capable of generating ROS in cancer cells [20]. Hence, experiments were carried out to measure the level of intracellular ROS in TPL and $\gamma$-irradiation (3 Gy) of MCF 7 cells. Using DCH-FDA fluorescent probe method, it was found that $0.25 \mathrm{mg} / \mathrm{ml}$ TPL induced almost two-fold greater increase in ROS generation in $\gamma$-irradiated MCF 7 cells, as compared to those treated with TPL/ $\gamma$-irradiation alone, which was highly significant (Figure 5), $\mathrm{p}<0.001$ ).

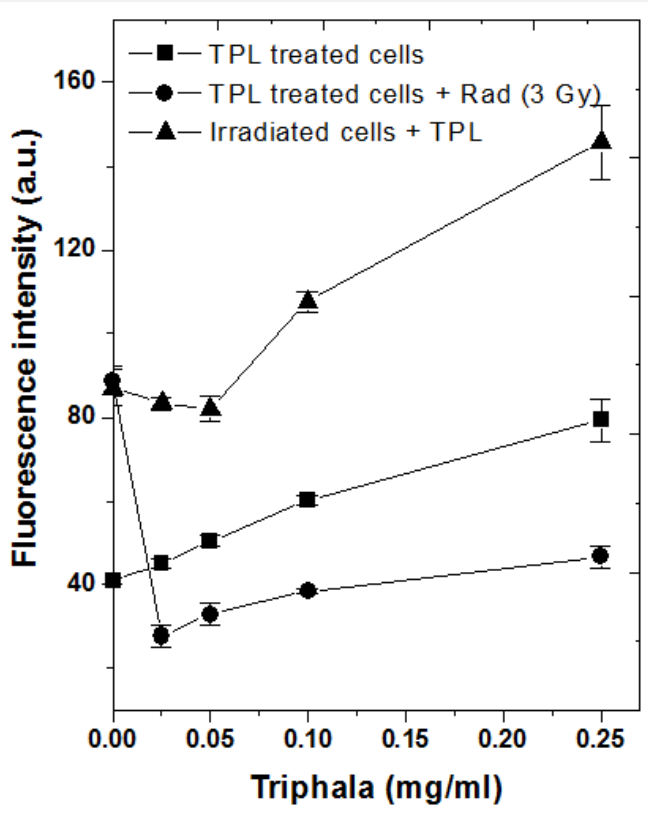

Figure 5: Estimation of TPL and radiation induced intracellular ROS. Cells $(3 \times 105)$ labelled with DCHFDA (2,7-dichlorodihydrofluorescein diacetate) were treated with increasing concentrations of either TPL alone or in combination with y-radiation (3 Gy, pre/post-drug treated) and incubated for $1 / 2 \mathrm{~h}$ in Phosphate buffered saline at $37^{\circ} \mathrm{C}$. Fluorescence intensity (lex $=490 \mathrm{~nm}$ and lex $=520 \mathrm{~nm}$ ) was measured using Fluorescence Spectrometer.

However, the observed increase of radiation-induced ROS by TPL was not observed when MCF 7 cells were pre-treated with the drug and it was present during irradiation. It was further found that in MCF 7 cells pre-treated with TPL, ROS generation induced by $\gamma$-irradiation was significantly lowered by 2 fold as compared to irradiated but without TPL treatment. This indicated that TPL enhanced intracellular ROS generation induced by $\gamma$-irradiation only when cells were treated with TPL post-irradiation. These results are in line with the observations from results of the clonogenic assay mentioned earlier. The results indicate that TPL probably potentiated $\gamma$-radiation induced toxicity in MCF 7 cells, post-irradiation through an ROS dependant apoptotic mechanism. To further confirm this and also to check if the mechanism of this combination treatment involves mitochondria, further experiments are warranted.

\section{TPL and $\boldsymbol{\gamma}$-radiation Induced mitochondrial membrane potential changes}

Changes in mitochondrial membrane permeability is another feature of apoptotic cell death and therefore, it was interesting to find if MCF 7 cells treated with TPL and $\gamma$-irradiation showed changes in mitochondrial membrane permeability. MCF 7 cells were either treated with TPL alone or in combination with 
$\gamma$-irradiation and observed under fluorescent microscope (Figure 6). It was found that fluorescence intensity of $\mathrm{DiOC}_{6}$, indicative of normal mitochondrial potential, as in untreated control cells, decreased progressively with increasing concentrations of TPL. MCF 7 cells treated with TPL, prior to irradiation did not show any decrease in mitochondrial membrane potential. However, 3 Gy $\gamma$-irradiated MCF 7 cells when treated with TPL showed greater loss of mitochondrial membrane potential as compared to MCF 7 cells treated with TPL alone. These results correlate well with the increased ROS generation and decreased clonogenic ability of MCF 7 cells on post-irradiation treatment with TPL, indicating that cytotoxicity induced by TPL may be due to its ability to induce oxidative stress causing perturbation in mitochondrial membrane potential.

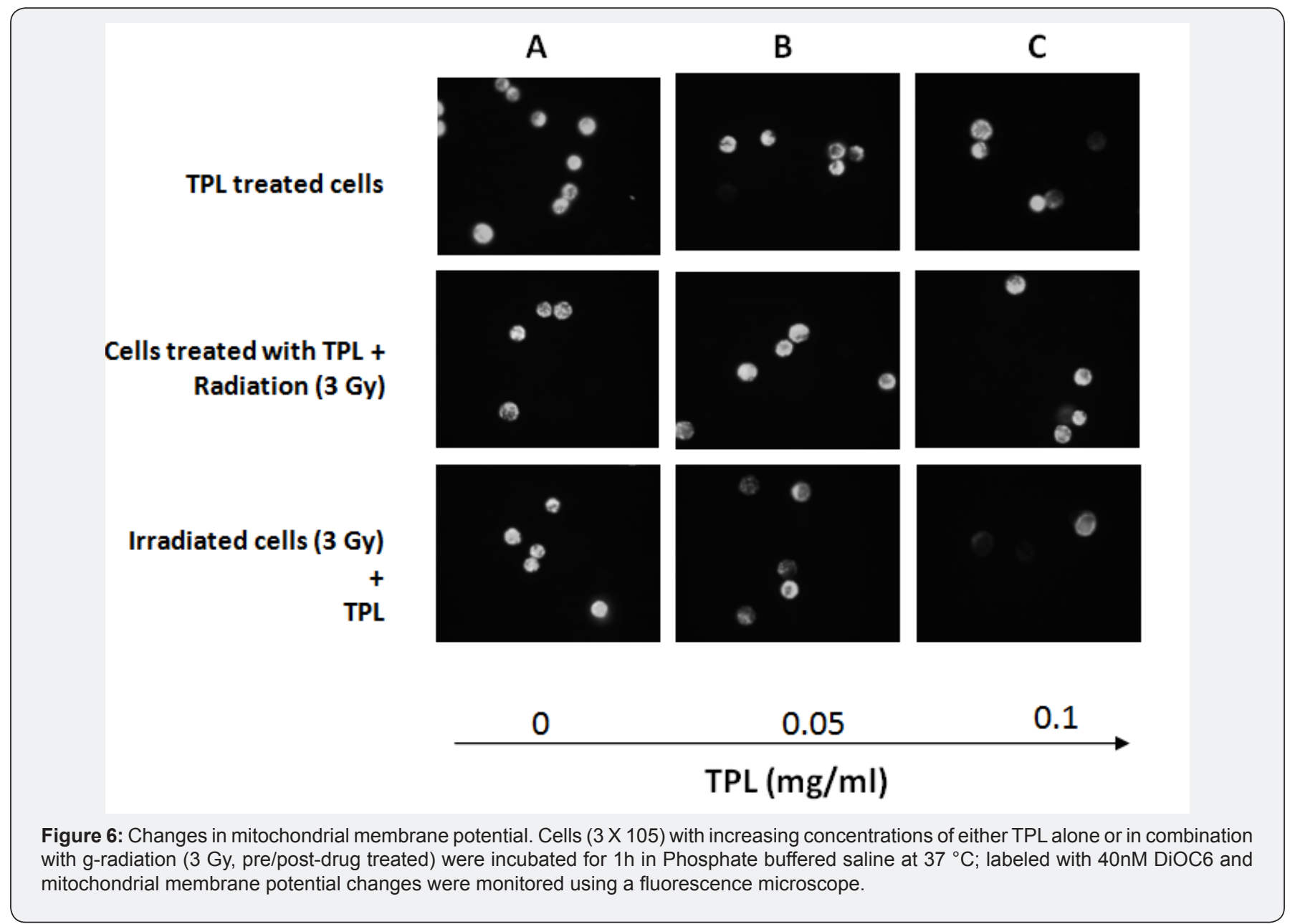

Our studies have shown that post-irradiation treatment of MCF 7 cells with TPL induced increased cytotoxicity by enhancing apoptosis probably through enhanced generation of ROS and decreased mitochondrial membrane permeability as compared to either TPL or radiation treatment alone. However, when MCF 7 cells were treated with TPL prior to irradiation and it was present during irradiation, the drug antagonized the effect of radiation. Investigations are warranted for the detailed mechanisms of TPL and radiation induced toxicity to understand the discrepancies observed when TPL was added to cancer cells before and after irradiation. Experiments have been carried out to examine validation of some of these in vitro results in animal tumor model.

\section{Effect of TPL and $\gamma$-radiation on tumor growth}

Combined effect of TPL and $\gamma$-irradiation on tumor growth of a murine transplantable thymic lymphoma and fibrosarcoma was investigated. It was found that both TPL and radiation alone were able to significantly reduce tumor growth volume of transplantable thymic lymphoma or barcl-95 as compared to the control. However, mice given a single dose, local $\gamma$-irradiation on the $7^{\text {th }}$ day after start of TPL feeding showed significantly greater reduction in tumor size as compared to the individual treatments. For example, on the $12^{\text {th }}$ day after tumor transplantation, tumor volume in the combined modality treatment with TPL and $\gamma$-irradiation was significantly smaller, $33 \%$ of control, as 
compared to that of TPL treatment alone, $49 \%$ of control and 3 Gy $\gamma$-irradiation treatment alone, $65 \%$ of control ( $p<0.05$, Figure 7 ).

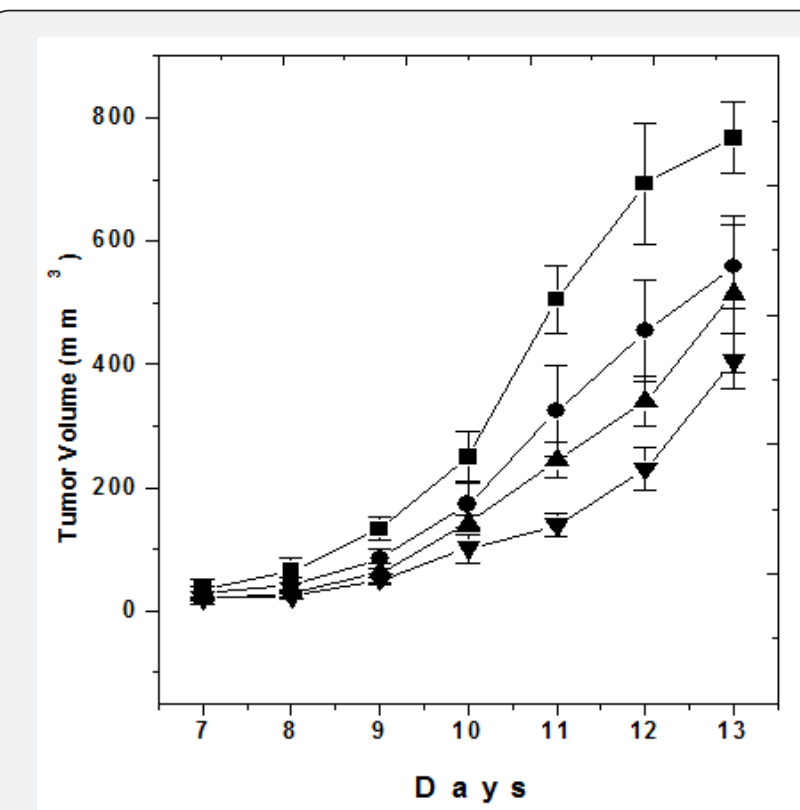

Figure 7: Effect of TPL and radiation on tumor volume of Swiss mice transplanted with barcl-95. Mice were divided into 4 different groups and were treated as described in 'Materials and Methods'. Tumor growth volume in the different groups; control ( $\boldsymbol{\square}), \gamma$-radiation alone $(\mathbf{O})$, TPL treatment alone $(\boldsymbol{\Lambda})$ $\gamma$-radiation and TPL combined treatment $(\boldsymbol{\nabla})$ were measured.

Studies on the radio-resistant mouse tumor fibrosarcoma showed that neither TPL nor $\gamma$-radiation individually nor in combination were able to induce significant tumor growth delay as compared to the control mice indicating that probably, TPL and $\gamma$-radiation induce tumor growth delay in vivo by similar mechanisms (Figure 8).

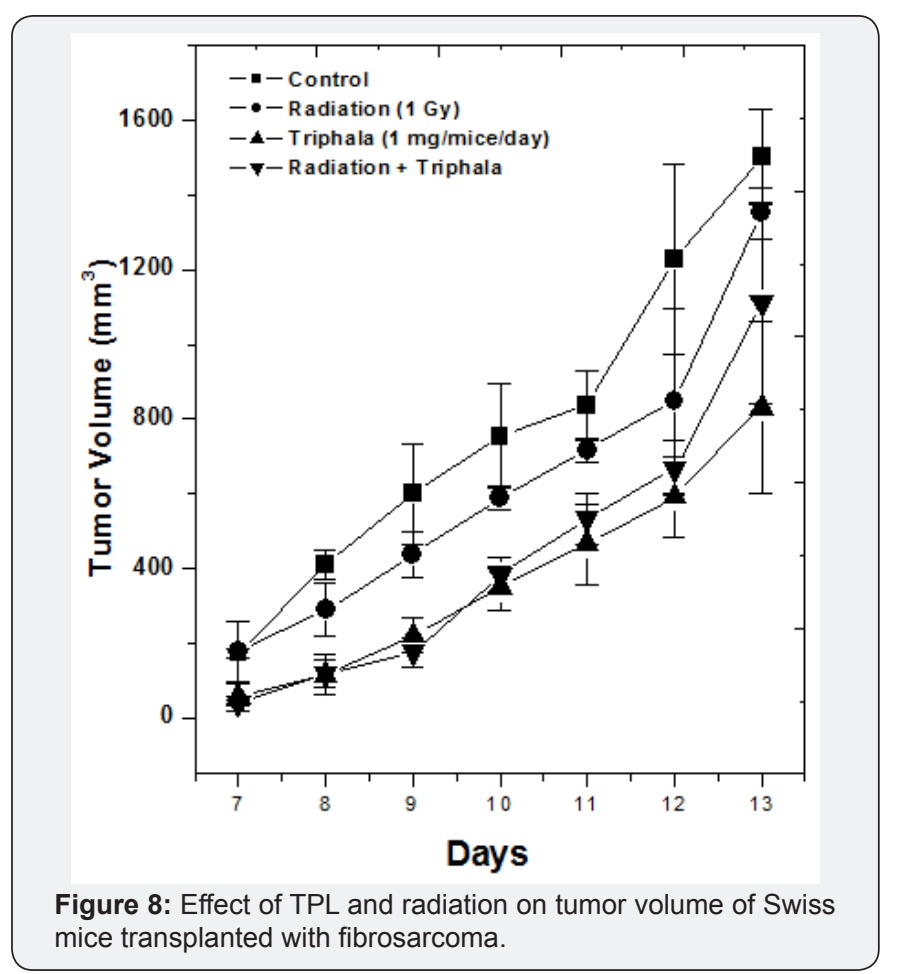

It can be concluded that in vitro, post-irradiation treatment with TPL sensitized human breast cancer cells, MCF 7 to $\gamma$-radiation whereas pre-treatment of MCF 7 cells with TPL antagonized the cytotoxic effects of radiation. The combination treatment of MCF 7 cells with $\gamma$-radiation enhanced apoptosis as compared to the individual treatments, probably involving ROS dependant mechanism. In vivo, combination treatment of TPL and $\gamma$-irradiation induced greater tumor growth delay in transplantable thymic lymphoma solid tumors as compared to that of individual treatments alone. TPL and $\gamma$-radiation treatment of radio resistant fibrosarcoma tumor, showed no reduction in tumor growth and it can be concluded that neither TPL nor radiation, either alone or in combination were effective in inducing tumor growth delay.

There is a great need for developing drugs for tumor radio sensitization with minimal or no toxicity towards normal cells/ tissues. TPL was found to be non-toxic towards a variety of normal cells [20] and was found to protect mice from radiation-induced lethality as described in [23]. These results suggest that TPL enhanced radiation-induced toxicity in tumor cells and its ability to protect mice and normal cells from radiation, may prove it an ideal candidate with potential as a radiosensitizer for cancer radiotherapy in clinic.

\section{Conclusion}

Our data show that treatment with TPL post irradiation enhanced cytotoxicity and decreased clonogenic ability of MCF-7 breast cancer cells through an ROS dependent apoptotic mechanism. Oral feeding of TPL for 7 days before and after $\gamma$-irradiation significantly reduced the tumor volume in mice transplanted with a radiation responsive transplantable thymic lymphoma, barcl-95. However, this ability of TPL to increase tumor cytotoxicity was not evident in the radio-resistant fibrosarcoma tumors. Hence it can be concluded that TPL does exert radiosensitizing ability in certain tumor cells, both in vitro as well as in vivo, mechanisms of which should be further investigated in detail. Results from these investigations can lead to a TPL based radiosensitizer that is selectively toxic to tumor cells.

\section{References}

1. Chen HHW, Kuo MT (2017) Improving radiotherapy in cancer treatment: Promises and challenges. Oncotarget 8(37): 62742-62758.

2. Luzhna L, Golubov A, Ilnytskyy S, Chekhun VF, Kovalchuk O (2013) Molecular mechanisms of radiation resistance in doxorubicin-resistant breast adenocarcinoma cells. Int J Oncol 42(5): 1692-1708.

3. Lebedeva IV, Su ZZ, Sarkar D, Fisher PB (2003) Restoring apoptosis as a strategy for cancer gene therapy: focus on p53 and mda-7. Semin Cancer Biol 13(2): 169-178.

4. Zhao J, Du F, Luo Y, Shen G, Zheng F, et al. (2015) The emerging role of hypoxia-inducible factor-2 involved in chemo/radioresistance in solid tumors. Cancer Treat Rev 41(7): 623-633.

5. Colliez F, Gallez B, Jordan BF (2017) Assessing Tumor Oxygenation for Predicting Outcome in Radiation Oncology: A Review of Studies Correlating Tumor Hypoxic Status and Outcome in the Preclinical and Clinical Settings. Front Oncol 7: 10. 


\section{Cancer Therapy \& Oncology International Journal}

6. Overgaard J, Hansen HS, Andersen AP, Hjelm-Hansen M, Jorgensen K, et al. (1989) Misonidazole combined with split-course radiotherapy in the treatment of invasive carcinoma of larynx and pharynx: report from the DAHANCA 2 study. Int J Radiat Oncol Biol Phys 16(4): 10651068.

7. Weiner LM, Colarusso P, Goldberg M, Dresler C, Coia LR (1997) Combined-modality therapy for esophageal cancer: phase I tria of escalating doses of paclitaxel in combination with cisplatin, 5 -fluorouracil, and high-dose radiation before esophagectomy. Semin Oncol. 24(6 Suppl 19): S19-93-S19-95.

8. Goldberg M, Farma J, Lampert C, Colarusso P, Coia L, et al. (2003) Survival following intensive preoperative combined modality therapy with paclitaxel, cisplatin, 5-fluorouracil, and radiation in resectable esophageal carcinoma: a phase I report. J Thorac Cardiovasc Surg 126(4): 1168-1173.

9. Nambiar D, Rajamani P, Singh RP (2011) Effects of phytochemicals on ionization radiation-mediated carcinogenesis and cancer therapy. Mutat Res. 728(3): 139-157.

10. Hillman GG, Wang Y, Kucuk O, Che M, Doerge DR, et al. (2004) Genistein potentiates inhibition of tumor growth by radiation in a prostate cancer orthotopic model. Mol Cancer Ther 3(10): 1271-1279.

11. Zoberi I, Bradbury CM, Curry HA, Bisht KS, Goswami PC, et al. (2002) Radiosensitizing and anti-proliferative effects of resveratrol in two human cervical tumor cell lines. Cancer Lett 175(2): 165-173.

12. Girdhani S, Bhosle SM, Thulsidas SA, Kumar A, Mishra KP (2005) Potential of radiosensitizing agents in cancer chemo-radiotherapy. J Cancer Res Ther 1(3): 129-131.

13. Gupta SC, Prasad S, Kim JH, Patchva S, Webb LJ, et al. ( 2011) Multitargeting by curcumin as revealed by molecular interaction studies. Nat Prod Rep 28(12): 1937-1955.
14. Enomoto A, Yamada J, Morita A, Miyagawa K (2017) Bisdemethoxycurcumin enhances X-ray-induced apoptosis possibly through p53/Bcl-2 pathway. Mutat Res 815: 1-5.

15. Pandey BN, Mishra KP (2003) In vitro studies on radiation induced membrane oxidative damage in apoptotic death in mouse thymocytes. Intl J Low Radiat 1: 113-119.

16. Ha SW, Yi CJ, Cho CK, Cho MJ, Shin KH, et al. (1996) Enhancement of radiation effect by Ginkgo biloba extract in $\mathrm{C} 3 \mathrm{H}$ mouse fibrosarcoma. Radiother Oncol 41(2): 163-167.

17. Chendil D, Ranga RS, Meigooni D, Sathishkumar S, Ahmed MM (2004) Curcumin confers radiosensitizing effect in prostate cancer cell line PC-3. Oncogene 23(8): 1599-1607.

18. Sarkar FH, Li Y (2004) Cell signaling pathways altered by natural chemopreventive agents. Mutat Res 555(1-2): 53-64.

19. Liu RH (2004) Potential synergy of phytochemicals in cancer prevention: mechanism of action. J Nutr 134(12 Suppl): S3479-S3485.

20. Sandhya T, Lathika KM, Pandey BN, Mishra KP (2006) Potential of traditional ayurvedic formulation, TPL, as a novel anticancer drug. Cancer Lett 231(2): 206-214

21. Sandhya T, Mishra KP (2006) Cytotoxic response of breast cancer cell lines, MCF 7 and T 47 D to TPL and its modification by antioxidants. Cancer Lett 238(2): 304-313.

22. Ahire V, Kumar A, Mishra KP, Kulkarni G (2017) Ellagic Acid Enhances Apoptotic Sensitivity of Breast Cancer Cells to $\gamma$-Radiation. Nutr Cancer 69(6): 904-910.

23. Sandhya T, Lathika KM, Pandey BN, Bhilwade HN, Chaubey RC, et al. (2006) Protection against radiation oxidative damage by Triphala. Mutation Res 609(1): 17-25.

\section{Your next submission with Juniper Publishers will reach you the below assets}

Commons Altribution 4.0 License

DOI: 10.19080/CTOIJ.2018.11.555802
- Quality Editorial service

- Swift Peer Review

- Reprints availability

- E-prints Service

- Manuscript Podcast for convenient understanding

- Global attainment for your research

- Manuscript accessibility in different formats

( Pdf, E-pub, Full Text, Audio)

- Unceasing customer service

Track the below URL for one-step submission https://juniperpublishers.com/online-submission.php 